\title{
CCL2 influences the sensitivity of lung cancer A549 cells to docetaxel
}

\author{
TING WANG $^{1 *}$, QINGYUAN ZHAN $^{2}$, XIAODONG PENG $^{3 *}$, ZHIMIN QIU $^{4 *}$ and TIANTIAN ZHAO ${ }^{*}$ \\ ${ }^{1}$ Department of Oncology, The People's Hospital of Nanchang County, Nanchang, Jiangxi 330200; \\ ${ }^{2}$ Department of Internal Medicine 2, Tumor Hospital of Jiangxi Province; ${ }^{3}$ Department of Oncology, \\ The First Affiliated Hospital of Nanchang University; ${ }^{4}$ Department of Internal Medicine 6, \\ Tumor Hospital of Jiangxi Province; ${ }^{5}$ Department of Respiratory Medicine, \\ The First Affiliated Hospital of Nanchang University, Nanchang, Jiangxi 330006, P.R. China
}

Received August 10, 2016; Accepted March 9, 2018

DOI: $10.3892 /$ ol.2018.8769

\begin{abstract}
Lung cancer is one of the most common malignant tumor types globally. Acquisition of chemoresistance in lung cancer cells is the primary cause of chemotherapy failure. Inflammatory chemokine $\mathrm{C}-\mathrm{C}$ motif chemokine ligand 2 (CCL2) has been reported to be involved in the progression of cancer and drug resistance. However, its function in docetaxel (DTX) resistance of lung cancer remains unclear. In the present study, the mechanism underlying DTX-induced drug resistance was investigated. Reverse transcription-quantitative polymerase chain reaction and western blot analysis revealed that DTX treatment increased the mRNA and protein expression of CCL2 in lung cancer A549 cells. CCL2 was knocked down by small interfering RNA or was overexpressed by recombinant CCL2 lentivirus, and cell viability was determined. An MTT assay indicated that CCL2 downregulation decreased the viability of A549 cells and augmented the DTX-induced cytotoxicity, whereas CCL2 upregulation protected A549 cells from DTX-induced cytotoxicity. Additionally, it was revealed that CCL2 overexpression activated phosphoinositide 3-kinase $(\mathrm{PI} 3 \mathrm{~K}) /$ protein kinase B (AKT) signaling and inhibited apoptosis-associated protein caspase-3 activation and B-cell lymphoma 2 (Bcl-2) phosphorylation at $\mathrm{Ser}^{70}$ induced by DTX, and enhanced DTX-induced Bcl-2-associated death promoter phosphorylation at $\mathrm{Ser}^{112}$. PI3K/AKT inhibitor LY294002 restored DTX-induced caspase-3 activation and Bcl-2 phosphorylation, reversed the effect of CCL2 on the viability of A549 cells and enhanced DTX-induced cytotoxicity. These
\end{abstract}

Correspondence to: Dr Qingyuan Zhan, Department of Internal Medicine 2, Tumor Hospital of Jiangxi Province, 519 Beijing East Road, Nanchang, Jiangxi 330006, P.R. China

E-mail: qingyzhanzz@163.com

*Contributed equally

Key words: C-C motif chemokine ligand 2, lung cancer, viability, docetaxel, phosphoinositide 3-kinase/protein kinase B signaling results demonstrated that chemoresistance may be mediated by cell stress responses involving CCL2 expression, suggesting that CCL2 may be a potential target for enhancing the therapeutic effect of DTX in lung cancer.

\section{Introduction}

Lung cancer is the leading cause of cancer-associated mortality globally, with the highest mortality rate due to abnormal cell proliferation and a high metastasis rate in 2014 (1). Chemotherapy is the standard treatment for advanced lung cancer with high metastatic ability (2). However, resistance to drugs is the most notable limitation of chemotherapy $(3,4)$. Therefore, understanding the mechanisms underlying the cellular response and drug resistance of cancer is required in order to improve chemotherapeutic efficacy. Docetaxel (DTX) is a well-established anti-mitotic chemotherapy agent that functions by interfering with cell division (5). It is used to treat a number of cancer types including metastatic or advanced breast, prostate, thyroid, gastric, ovarian and lung cancer based on its pro-apoptosis potential and its inhibitory effect on angiogenesis and cell viability (6-14). DTX has also been demonstrated to upregulate growth/differentiation factor 15 and results in chemoresistance in prostate cancer (15). However, DTX-induced cellular resistance responses in lung cancer remain unknown.

Inflammation is involved in the progression and development of malignancies (16). Balance between proand anti-inflammatory mechanisms is responsible for tissue homeostasis (17). However, an abnormal imbalance is often associated with the development of cancer accompanied by an inflammatory response (18-21). Inflammatory responses are mediated by specific cytokines and chemokines commonly expressed by immune cells; however, cancer cells have also been reported to produce cytokines and chemokines in order to promote tumorigenesis in an inflammatory microenvironment (22). C-C motif chemokine ligand 2 (CCL2) is a small chemokine, also known as monocyte chemoattractant protein 1 , belonging to the CC chemokine family (23). CCL2 has been reported to be secreted and to recruit immune cells to the sites of inflammation produced by either tissue injury or 
infection $(24,25)$ and may also stimulate angiogenesis through a direct effect on endothelial cells (26). CCL2 has additionally been revealed to be associated with the development of cancer and to be highly expressed in cancer cells (27). The majority of studies of CCL2 focus on its effects on the migration and metastasis of tumor cells, whereas its effects on cell proliferation and viability have not been sufficiently explored. It has been revealed that a CCL2 blockade may enhance the effect of therapeutic methods on CCL2-induced inflammatory diseases and cancer (28). Targeting CCL2 with blocking antibodies has been demonstrated to suppress lung and bone metastases in vivo, exhibiting a novel therapeutic approach for cancer $(29,30)$. Furthermore, it has been demonstrated that CCL2 inhibition decreases the volume of subcutaneous tumor xenografts in mice (31). Additionally, CCL2 is involved in DTX-induced chemoresistance in prostate cancer (32), and CCL2 inhibition augments DTX-induced inhibitory effects on the growth of prostate cancer (33). CCL2 blockades have also been demonstrated to inhibit tumor growth in lung cancer $(34,35)$. However, the role of CCL2 in the sensitivity of lung cancer to DTX remains unclear.

In the present study, lung cancer A549 cells were treated with DTX, and then CCL2 expression prior to and following exposure to DTX was investigated in order to identify whether CCL2 is involved in the molecular mechanism underlying DTX-induced resistance.

\section{Materials and methods}

Cell culture and reagents. The human non-small cell lung cancer cell line A549 was purchased from the American Type Culture Collection (Manassas, VA, USA). Cells were cultured in Kaighn's modification of Ham's F12 (F12K) medium (Gibco; Thermo Fisher Scientific, Inc., Waltham, MA, USA) supplemented with $10 \%$ fetal bovine serum (FBS; Lonza Group, Ltd., Basel, Switzerland), $5 \mathrm{mM}$ non-essential amino acids, $5 \mathrm{mM}$ L-glutamine, $100 \mathrm{U} / \mathrm{ml}$ penicillin and streptomycin (Invitrogen; Thermo Fisher Scientific, Inc.), in a humidified $5 \% \mathrm{CO}_{2}$ incubator at $37^{\circ} \mathrm{C}$. For serum-starved culture, cells were first maintained in F12K medium with FBS for $24 \mathrm{~h}$, and then PBS was used to wash the cells three times and was replaced with F12K without FBS. DTX was purchased from Sigma-Aldrich; Merck KGaA (Darmstadt, Germany), dissolved in dimethylsulfoxide (DMSO). The phosphoinositide 3-kinase (PI3K)/protein kinase B (AKT) inhibitor LY294002 was purchased from Enzo Life Sciences, Inc. (Farmingdale, NY, USA).

Reverse transcription-quantitative polymerase chain reaction (RT-qPCR). Total RNA was extracted from A549 cells using an RNA isolation kit (A\&A Biotechnology, Gdynia, Poland) according to the manufacturer's protocol. cDNA was obtained by RT using a RevertAid ${ }^{\text {TM }}$ First Strand cDNA synthesis kit (Fermentas; Thermo Fisher Scientific, Inc.) according to the manufacturer's protocol and was amplified using a TaqMan ${ }^{\circledR}$ Gene Expression assay (Applied Biosystems; Thermo Fisher Scientific, Inc.) with fluorigenic carboxyfluorescein-labeled probes using the specific primers for the target protein CCL2. PCR involved 40 amplification cycles of $94^{\circ} \mathrm{C}$ for $10 \mathrm{sec}, 53^{\circ} \mathrm{C}$ for $30 \mathrm{sec}$ and $72^{\circ} \mathrm{C}$ for $40 \mathrm{sec}$, followed by final extension at $72^{\circ} \mathrm{C}$ for $10 \mathrm{~min}$. Primer sequences for CCL2 were: 5'-GAA CACACTCAGCGCAGTTA-3' (forward primer) and 5'-CAC CCACCCTCTCTTTGATTAC-3' (reverse primer). Primer sequences for GAPDH were 5'-CATGGCCTTCCGTGTTCC TA-3' (forward primer) and R, 5'-CCTGCTTCACCACCT TCTTGAT-3' (reverse primer). Fluorescence detection was performed using the ABI PRISM 7700 Sequence Detector (PerkinElmer; Applied Biosystems; Thermo Fisher Scientific, Inc.). The mRNA expression of CCL2 was calculated using the formula $2^{-\Delta \Delta \mathrm{Cq}}(36)$ and was normalized to the level of GAPDH. The relative level of CCL2 mRNA was presented as a percentage of the control.

Western blot analysis. A total of $5 \times 10^{5}$ A549 cells were plated in a culture dish and grown to $80 \%$ confluence, and then treated with 0,2 and $4 \mathrm{nM}$ of DTX. The cells were then washed twice with PBS and homogenized with M-PER Mammalian Protein Extraction reagent (Pierce; Thermo Fisher Scientific, Inc.), according to the manufacturer's protocol. Following centrifugation at $12,000 \mathrm{x}$ g for $10 \mathrm{~min}$ at $4^{\circ} \mathrm{C}$, the supernatant was collected and quantified using a bicinchoninic acid quantification kit (Beyotime Institute of Biotechnology, Haimen, China). The proteins (50 $\mu \mathrm{g})$ were separated by SDS-PAGE (12\% gel; Beijing Solarbio Science \& Technology Co., Ltd., Beijing, China) and transferred onto polyvinylidene fluoride membranes (EMD Millipore, Billerica, MA, USA). The membranes were blocked with 5\% non-fat dried milk in Tris-buffered saline with $0.1 \%$ Tween-20 for $1 \mathrm{~h}$ at room temperature, and incubated with the following specific primary antibodies overnight at $4^{\circ} \mathrm{C}$ : Anti-CCL2 antibody (cat. no. MAB679; 1:500; R\&D Systems, Inc., Minneapolis, MN, USA), anti-B-cell lymphoma 2 (Bcl-2, cat. no. sc7382; 1:500) and anti-GAPDH antibodies (cat. no. sc-365062; 1:3,000; Santa Cruz Biotechnology, Inc., Dallas, TX, USA), anti-phospho-Bcl-2 (pSer ${ }^{70}$, cat. no. 2871; 1:1,000), anti-Bcl-2-associated death promoter (Bad; cat. no. 9292; 1:1,000), anti-phospho-Bad (pSer ${ }^{12}$, cat. no. 9291; 1:1,000), anti-protein kinase B (AKT; cat. no. 9272; 1:1,000) and anti-phospho-AKT (pSer ${ }^{473}$; cat. no. 9271; 1:1,000) antibodies (Cell Signaling Technology, Inc., Danvers, MA, USA). This was followed by incubation with horseradish peroxidase-conjugated secondary antibodies goat anti-mouse (cat. no. sc-2005; 1:2,000) and anti-rabbit immunoglobulin G (cat. no. sc-2004; 1:2,000; both Santa Cruz Biotechnology, Inc.) for $2 \mathrm{~h}$ at room temperature. Then the membranes were washed with Tris-buffered saline with $0.1 \%$ Tween-20 three times for $5 \mathrm{~min}$ each time. Development was performed using an enhanced chemiluminescence-detecting reagent (GE Healthcare, Chicago, IL, USA). The protein blots were quantified by densitometry using QuantityOne software (version 4.6.2; Bio-Rad Laboratories, Inc., Hercules, CA, USA), and the amounts were expressed relative to the internal reference GAPDH.

Coomassie blue stain. The staining solution containing $0.1 \%$ Coomassie ${ }^{\circledR}$ R-250 (Thermo Fisher Scientific Inc., Rochester, NY, USA) was prepared in $40 \%$ ethanol and $10 \%$ acetic acid. Following SDS-PAGE as described above, gel is incubated in a staining container containing $100 \mathrm{ml}$ Coomassie ${ }^{\circledR}$ Blue R-250 staining solution at $95^{\circ} \mathrm{C}$ for $10 \mathrm{~min}$ 

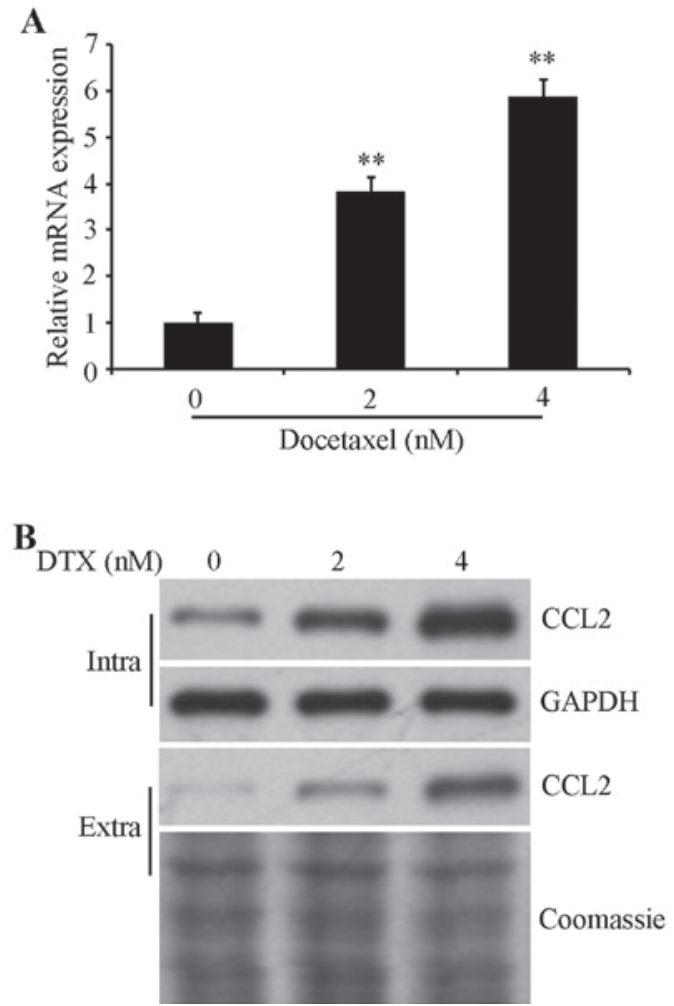

Figure 1. DTX treatment increases the expression of CCL2. A549 cells were treated with 0,2 and $4 \mathrm{nM}$ DTX for $72 \mathrm{~h}$. (A) CCL 2 mRNA expression levels were detected using the reverse transcription-quantitative polymerase chain reaction. (B) Intracellular/extracellular CCL2 protein expression was detected using western blot analysis using an anti-CCL2 antibody. Intracellular and extracellular CCL2 loading was normalized using GAPDH and a Coomassie blue stain, respectively. ${ }^{* *} \mathrm{P}<0.01$ vs. DTX-untreated control DTX, docetaxel; CCL2, C-C motif chemokine ligand 2; Intra, intracellular; Extra, extracellular.

and then gently agitated for $15 \mathrm{~min}$ at room temperature. The gel was rinsed once with deionized water. A destaining solution containing $10 \%$ ethanol and $7.5 \%$ acetic acid was prepared. The stained gel was placed in a staining container containing $100 \mathrm{ml}$ destaining solution, gently agitated at room temperature on an orbital shaker until the desired background was achieved.

CCL2 siRNA and overexpression. CCL2 small interfering RNA (siRNA) and control siRNA were obtained from GE Healthcare Dharmacon, Inc. (Lafayette, CO, USA). The sequence of CCL2 siRNA: 5'-CTCGCGAGCTATAGA AGAA-3'. The small interference RNA of negative control ( $\operatorname{siCtrl):~Sense,~5'-UUCUCCGAACGUGUCACGUTT-3';~}$ Antisense, 5'-ACGUGACACGUUCGGAGAATT-3'. A total of $2 \times 10^{4}$ A549 cells were seeded in 12-well plate and cultured for $24 \mathrm{~h}$, and then transfected using $100 \mathrm{nmol}$ siRNA and $5 \mu \mathrm{l}$ Lipofectamine $^{\mathrm{TM}} 2000$ (Invitrogen; Thermo Fisher Scientific, Inc.) for $48 \mathrm{~h}$ according to the manufacturer's protocol. Cells were grown for a further $48 \mathrm{~h}$ following transfection, and then were lysed in lysis buffer [50 mM Tris- $\mathrm{HCl}$ (pH 7.4), $1 \mathrm{mM}$ EDTA, 1\% NP40, 150 mM NaCl, 10 mM NaF, 1 mM Na3VO4] containing a protease inhibitor cocktail (Roche, NJ, USA) and used for protein expression analysis. A recombinant lentiviral vector containing CCL2 and control vector were obtained from the Department of Medicine, Oregon Health \& Science University (Portland, OR, USA). The lentiviral infection and establishment of A549 cells with stable CCL2 expression was performed as previously described (37).

Cell viability assay. A549 cell viability was evaluated using an MTT assay (Sigma Aldrich; Merck KGaA). MTT assay was performed using 96-well plate according to the manufacturer's protocol. In total, $5 \times 10^{4}$ cells/well were cultured at $37^{\circ} \mathrm{C}$ with $5 \% \mathrm{CO}_{2}$ overnight and $0,2,4$ or $15 \mathrm{nM}$ DTX was added to the culture for 6 days or $4 \mathrm{nM}$ for $48 \mathrm{~h}$. Then cells were incubated with $20 \mu \mathrm{l} \mathrm{MTT}\left(5 \mathrm{mg} / \mathrm{ml}\right.$ in PBS) for $4 \mathrm{~h}$ at $37^{\circ} \mathrm{C}$, and then cells were lysed for $10 \mathrm{~min}$ by the addition of $200 \mu \mathrm{l}$ DMSO (OriGene Technologies, Inc., Rockville, MD, USA) used to dissolve the formazan crystals. Absorbance was measured at $570 \mathrm{~nm}$ using a Rainbow microplate reader (Tecan Group, Ltd., Mannedorf, Switzerland). Cell viability was expressed as a percentage of the untreated control.

Caspase-3 activity assay. Caspase-3 activity was evaluated in A549 cells using the human active caspase-3 ELISA kit (cat. no. KM300; R\&D Systems, Inc.) according to the manufacturer's protocol. In total, $5 \times 10^{5}$ cells/well were cultured in 6 -well plates for $24 \mathrm{~h}$ at $37^{\circ} \mathrm{C}$. Cells were treated with or without $4 \mathrm{nM}$ DTX/5 $\mu \mathrm{M}$ LY294002 for $48 \mathrm{~h}$ at $37^{\circ} \mathrm{C}$. Subsequently, the cells were lysed with Extraction Buffer (included in the human active caspase-3 ELISA kit) and analyzed according to the manufacturer's protocol. Absorbance was measured at $570 \mathrm{~nm}$ using a microplate reader.

Statistical analysis. Data are expressed as the mean \pm standard error of the mean. Statistical analyses were performed using SPSS software (version 11.0; SPSS, Inc., Chicago, IL, USA). All experiments were performed at least three times. One-way analysis of variance (ANOVA) was used to assess differences between groups. Duncan's new multiple range test as a post hoc test was used following ANOVA for pairwise comparison followed by Bonferroni's correction. $\mathrm{P}<0.05$ was considered to indicate a statistically significant difference.

\section{Results}

CCL2 is increased in DTX-treated A549 cells. To investigate the role of CCL2 in regulating the DTX resistance of lung cancer, CCL2 expression in was detected in A549 cells prior to and following DTX treatment. Cells were exposed to 0,2 and $4 \mathrm{nM}$ DTX for $72 \mathrm{~h}$, and then the mRNA expression level was determined using RT-qPCR and protein expression was examined using western blot analysis. The results confirmed that the mRNA expression levels of CCL2 were significantly increased $(\mathrm{P}<0.01$; Fig. 1A) and the intracellular/extracellular protein expression of CCL2 were increased in DTX-treated cells in a dose-dependent manner compared with non-treated control cells (Fig. 1B), suggesting that CCL2 is associated with DTX-induced resistance in lung cancer A549 cells.

CCL2 downregulation augments the inhibition of cell viability by DTX. To confirm the role of DTX-induced CCL2 expression in the chemoresistance of lung cancer, CCL2 expression was 
knocked down using siRNA in A549 cells. Cells were transfected with CCL2 siRNA or control siRNA for $48 \mathrm{~h}$ followed by $24 \mathrm{~h}$ recovery, and then were treated with or without $4 \mathrm{nM}$ DTX for another $48 \mathrm{~h}$. RT-qPCR and western blot analysis were performed to determine CCL2 mRNA expression levels and protein expression. The data revealed that DTX-induced CCL2 expression was substantially decreased in CCL2 siRNA treated cells compared with siRNA control-transfected cells (Fig. 2A and B). Next, following transfection, CCL2-silenced and non-silenced A549 cells were maintained in serum-free medium with 0, 2 and $4 \mathrm{nM}$ DTX for 6 days. Cell viability was evaluated using an MTT assay. The results indicated that CCL2-silenced cells exhibited significantly decreased viability compared with non-silenced cells in groups treated with 0 and 4 nM DTX $(\mathrm{P}<0.05)$. Cell viability was also decreased by DTX in a concentration-dependent manner. Notably, CCL2 silencing in combination with $4 \mathrm{nM}$ DTX revealed a significantly increased viability inhibition compared with DTX alone or CCL2 siRNA alone ( $\mathrm{P}<0.01$; Fig. $2 \mathrm{C}$ ). These results imply that the DTX resistance response in lung cancer A549 cells may be caused by DTX-induced CCL2 expression, and CCL2 inhibition may attenuate DTX resistance and augment DTX-induced cytotoxicity.

CCL2 upregulation attenuates DTX cytotoxicity. To verify the role of CCL2 in DTX resistance of lung cancer A549 cells, an A549 cell line that stably overexpressed CCL2 was established using recombinant CCL2 lentiviruses. Western blot analysis revealed that CCL2 was effectively overexpressed in CCL2 lentivirus-infected cells and was increased compared with control lentivirus-infected cells (Fig. 3A). Viability of cells with CCL2 overexpression or empty control vectors was examined using an MTT assay. No significant differences were identified in cell viability between the two cell lines under serum-free culture conditions (Fig. 3B). When treated with 4 nM DTX for 6 days, CCL2-overexpressed cells exhibited a significantly increased cell viability compared with control cells ( $\mathrm{P}<0.05$; Fig. 3B). However, when cells were treated with a high concentration of DTX at $15 \mathrm{nM}$, CCL2 overexpression did not attenuate the inhibitory effect on cell viability induced by DTX, suggesting that the resistance response in A549 cells may be induced by DTX at a low concentration but not at a high concentration that caused the suppression of cell viability to sufficiently overcome the positive effect of CCL2 on cell viability.

CCL2 influences the activation of viability and apoptosisassociated signaling. To determine the mechanism underlying the CCL2-mediated DTX resistance response in lung cancer cells, cells with CCL2 overexpression or empty control vectors were treated with or without $4 \mathrm{nM}$ DTX for $48 \mathrm{~h}$ in serum-free culture medium. Western blot analysis results revealed that DTX treatment induced AKT phosphorylation at $\mathrm{Ser}^{473}$ compared with the control and CCL2 overexpression also substantially stimulated the activation of AKT compared with the control by promoting its phosphorylation at $\mathrm{Ser}^{473}$. DTX in combination with CCL2 notably enhanced AKT phosphorylation (Fig. 4A), suggesting that CCL2 mediated PI3K/AKT signaling activation serves an important function in the DTX induced resistance response. Next, activities of apoptosis-associated proteins including the anti-apoptotic protein $\mathrm{Bcl}-2$, pro-apoptotic
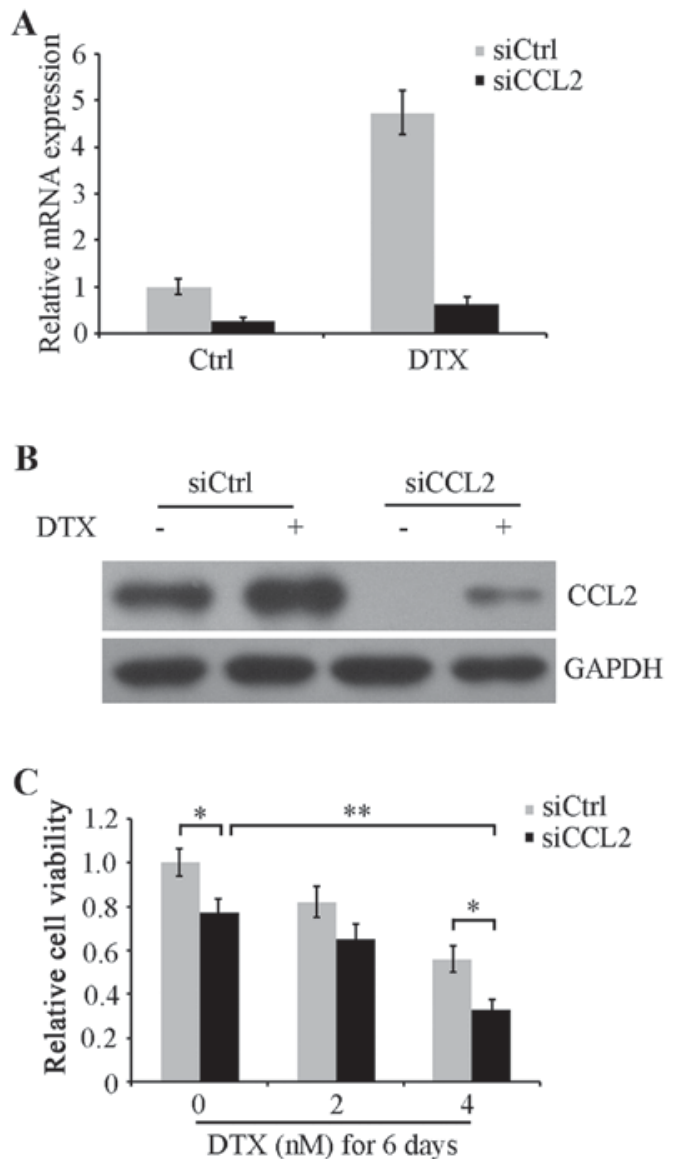

Figure 2. CCL2 downregulation augments DTX cytotoxicity. A549 cells were transfected with siRNA against CCL2 (siCCL2) or control siRNA (siCtrl) for $48 \mathrm{~h}$ and then were treated with $4 \mathrm{nM}$ DTX for another $48 \mathrm{~h}$. Total mRNA and proteins were extracted from the cells, and then (A) the reverse transcription-quantitative polymerase chain reaction was used to determine CCL2 mRNA expression levels and (B) western blot analysis was used to detect CCL2 protein expression using an anti-CCL2 antibody. GAPDH was used as an internal reference. (C) CCL2-silenced (siCCL2) and non-silenced (siCtrl) A549 cells were maintained in serum-free medium with 0,2 and 4 nM DTX for 6 days. Cell viability was determined using an MTT assay. ${ }^{*} \mathrm{P}<0.05$ and ${ }^{* *} \mathrm{P}<0.01$ with comparisons shown by lines. CCL2, C-C motif chemokine ligand 2; DTX, docetaxel; siRNA, small interfering RNA; Ctrl, control.

protein Bad and caspase-3 were detected. Western blot analysis revealed that the phosphorylation of $\mathrm{Bcl}-2$ at $\mathrm{Ser}^{70}$ was induced by DTX, whereas its phosphorylation was attenuated by CCL2. Meanwhile, CCL2 enhanced the phosphorylation of the pro-apoptotic protein Bad at Ser ${ }^{112}$ induced by DTX (Fig. 4A). Additionally, a caspase-3 activity assay indicated that CCL2 significantly inhibited the activation of caspase- 3 induced by DTX (P<0.05; Fig. 4B). These data suggest that CCL2 attenuates DTX-induced cytotoxicity potentially by regulating the activities of the PI3K/AKT signaling pathway and these apoptosis-associated proteins.

Inhibition of PI3K/AKT signaling augments DTX cytotoxicity. In order to further confirm whether PI3K/AKT activation participated in regulating the activities of the aforementioned apoptosis-associated proteins, the PI3K/AKT-specific inhibitor LY294002 was used to inhibit this signaling pathway. Control, normal and CCL2-overexpressing cells were treated with or without $4 \mathrm{nM}$ DTX, or $4 \mathrm{nM}$ DTX combined with 
A

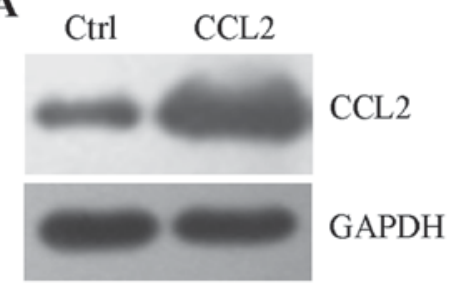

B

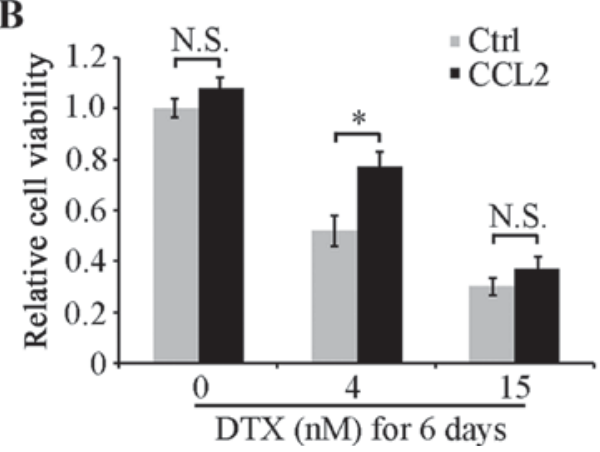

Figure 3. CCL2 upregulation attenuates DTX cytotoxicity. (A) Western blot analysis was used to determine CCL2 protein expression in CCL2 lentivirus-infected A549 cells (CCL2) and control lentivirus-infected cells (Ctrl). (B) CCL2-overexpressing and control cells were treated with 0, 4 or $15 \mathrm{nM}$ DTX for 6 days. Cell viability was examined using an MTT assay. ${ }^{*} \mathrm{P}<0.05$ with comparisons shown by lines. N.S., not significant; CCL2, C-C motif chemokine ligand 2; DTX, docetaxel; Ctrl, control.

$5 \mu \mathrm{M}$ LY294002 for $48 \mathrm{~h}$. Western blot analysis revealed that LY294002 restored the phosphorylation of Bcl-2 compared with CCL2-overexpressing cells treated with DTX alone, whereas Bad phosphorylation at Ser ${ }^{12}$ was unaffected, suggesting that it may be a target of other signaling molecules (Fig. 5A). Additionally, the activity of caspase-3 in CCL2-overexpressing cells treated with DTX was significantly restored by LY294002 (P<0.05; Fig. 5B). Therefore, it may be that DTX-induced CCL2 stimulates the PI3K/AKT signaling pathway to resist DTX-induced cytotoxicity. Next, cell viability was determined using an MTT assay. The results revealed that LY294002 enhanced DTX inhibition on cell viability in CCL2-overexpressing cells $(\mathrm{P}<0.05$; Fig. 5C), indicating that $\mathrm{PI} 3 \mathrm{~K} / \mathrm{AKT}$ is a promising target for improving the efficacy of chemotherapy.

\section{Discussion}

Lung cancer is a common malignancy with the highest mortality rate in the United States in 2014 (1). DTX is widely used as a cancer treatment (6-14). However, the emergence of chemotherapeutic resistance iTHs universal and DTX-resistance responses have been observed in a number of patients (15). In the present study, it was demonstrated that DTX induced a resistance response in lung cancer A549 cells and the underlying molecular mechanism was investigated. A comparison of mRNA and protein levels of the chemokine CCL2 prior to and following DTX treatment identified an increase in CCL2 in DTX-treated A549 cells. Additionally, it was revealed that CCL2 silencing augmented the inhibition of DTX on viability, whereas CCL2 upregulation protected A549 cells from DTX-induced cytotoxicity.
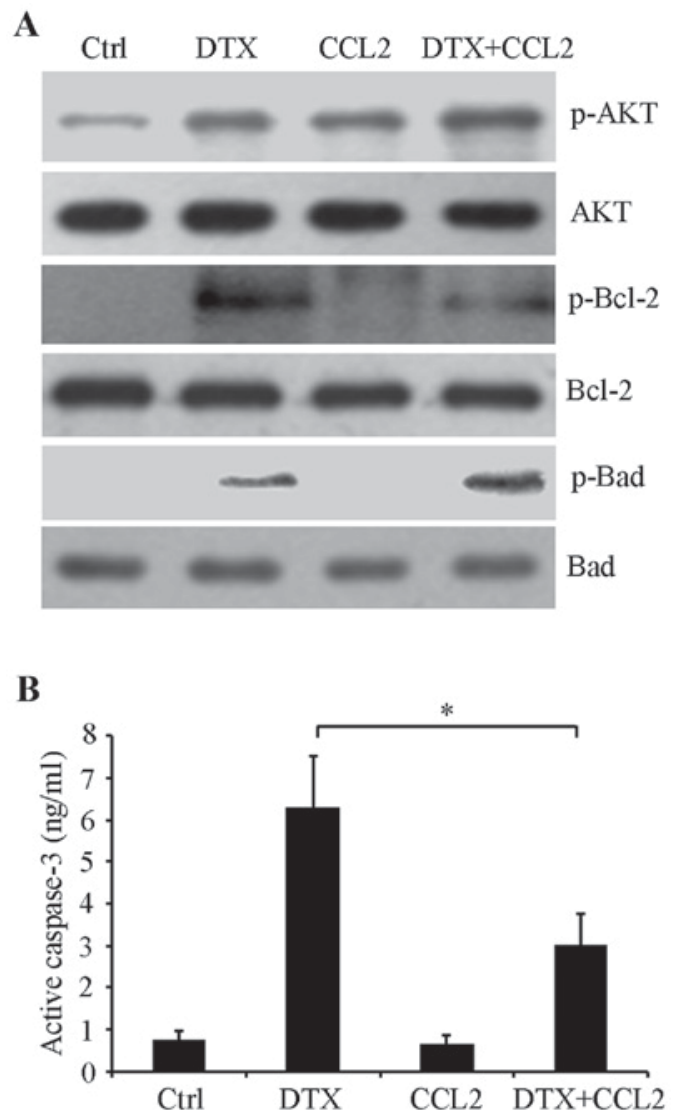

Figure 4. CCL2 regulates apoptosis-associated signaling. A549 cells with CCL2 overexpression or empty control vector were treated with or without $4 \mathrm{nM}$ DTX for $48 \mathrm{~h}$ in serum-free culture medium. (A) Western blot analysis was performed to detect AKT phosphorylation using specific antibodies against p-AKT $\left(\mathrm{pSer}^{473}\right), \mathrm{p}-\mathrm{Bcl}-2\left(\mathrm{pSer}^{70}\right)$ and $\mathrm{p}-\mathrm{Bad}\left(\mathrm{pSer}^{112}\right)$. Total AKT, Bcl-2 and Bad were used as loading controls. (B) Caspase-3 activity was detected using a human active caspase- 3 ELISA. " $\mathrm{P}<0.05$ with comparisons shown by lines. CCL2, C-C motif chemokine ligand 2; DTX, docetaxel; Ctrl, control; p-, phosphorylated; AKT, protein kinase B; Bcl-2, B-cell lymphoma 2; Bad, Bcl-2-associated death promoter.

PI3K/AKT signaling has been reported to be positively associated with cell viability and apoptosis resistance, and PI3K may promote tumor cell survival by triggering AKT activation (38-40). In the present study, it was indicated that DTX treatment or CCL2 overexpression, or the two combined, activated AKT by inducing AKT phosphorylation at $\mathrm{Ser}^{473}$, suggesting the involvement of PI3K/AKT signaling in a DTX-induced resistance response. AKT is able to directly control apoptosis by regulating phosphorylation to affect the activities of apoptosis-associated proteins including the pro-apoptotic Bad and caspase cascades (41-43). AKT may phosphorylate Bad at several sites to inactivate the pro-apoptotic function (44). It was revealed that DTX induced CCL2 and activated AKT, and CCL2 enhanced DTX-induced Bad phosphorylation at Ser ${ }^{112}$ leading to Bad inactivation, which blocked apoptosis. However, the PI3K/AKT inhibitor LY294002 did not alter Bad phosphorylation at Ser ${ }^{12}$, suggesting that Bad $\mathrm{Ser}^{112}$ may not be the target of PI3K/AKT in the resistance response. Additionally, DTX has been demonstrated to promote the phosphorylation of anti-apoptotic protein $\mathrm{Bcl}-2$ at $\mathrm{Ser}^{70}(45,46)$. It has also been revealed that $\mathrm{Bcl}-2$ phosphorylation abolishes its 
anti-apoptosis effect, resulting in caspase-3 activation and cellular apoptosis $(47,48)$. It was revealed that DTX induced Bcl-2 phosphorylation at $\mathrm{Ser}^{70}$ resulting in its inactivation and the activation of caspase-3 that triggered cell apoptosis, whereas CCL2 overexpression attenuated Bcl-2 phosphorylation and caspase- 3 activation induced by DTX, suggesting that CCL2 decreased DTX-induced cytotoxicity by blocking cell apoptosis. Additionally, it was indicated that the inhibition of PI3K/AKT by the inhibitor LY294002 augmented DTX treatment toxicity, implying that chemotherapy combined with PI3K/AKT inhibition may be more efficient for the treatment of lung cancer.

CCL2 may be regulated by multiple mechanisms. It has been reported that CCL2 expression is upregulated by DTX via c-Jun $\mathrm{N}$-terminal kinases (JNKs) and nuclear factor- $\mathrm{KB}$ $(\mathrm{NF}-\mathrm{kB})$ pathways in prostate cancer (32). Whether CCL2 was induced by DTX via JNK or NF- $\kappa B$ signaling pathways requires further studies. In addition, it has also been revealed that tumor protein p53 binds to CCL2, consequently significantly downregulating CCL2 promoter activity, and thus suppressing CCL2-induced subcutaneous tumor xenografts (49). CCL2 may be regulated by myeloid differentiation primary response 88 in murine mammary carcinomas and thus affect cell viability and metastasis (50). CCL2 was revealed to be involved in visfatin-mediated lung cancer NCI-H446 cells transendothelial migration and visfatin-induced CCL2 was attenuated by a specific inhibitor of PI3K/AKT signaling (51). CCL2 was also been revealed to be inhibited by atypical chemokine receptor D6 and then regulated cell viability in lung cancer A549 cells (52). The identity of the molecules involved in the modulation of CCL2 induced by DTX is yet to be determined.

Monoclonal antibodies against CCL2 have been administered in lung cancer immunotherapy models and have been identified to exhibit antitumor activity $(34,35)$. The results of the present study confirm this the effect of targeting CCL2 by siRNA in DTX treatment. These results also imply that targeting DTX-induced CCL2 expression combined with DTX may effectively decrease chemotherapy-induced resistance and improve drug efficacy in lung cancer.

\section{Acknowledgements}

Not applicable.

\section{Funding}

No funding was received.

\section{Availability of data and materials}

The datasets used and/or analyzed during the current study are available from the corresponding author on reasonable request.

\section{Authors' contributions}

TW, XP, ZQ and TZ were the major contributors in conception and design of the research and revision of manuscript for important intellectual content. Acquisition of data was
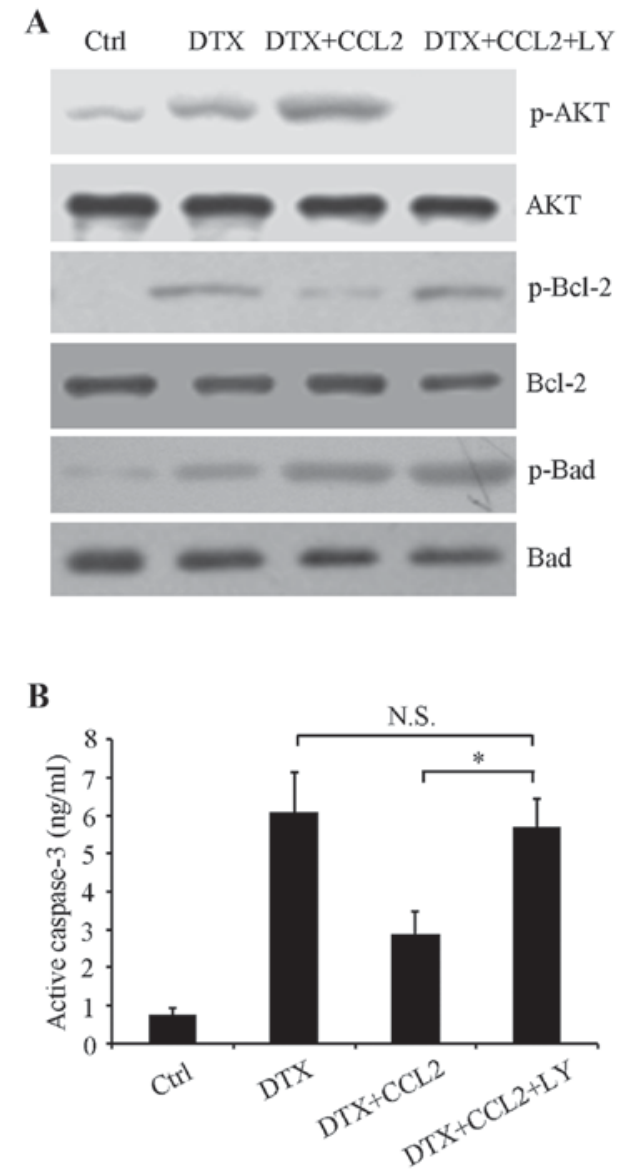

C

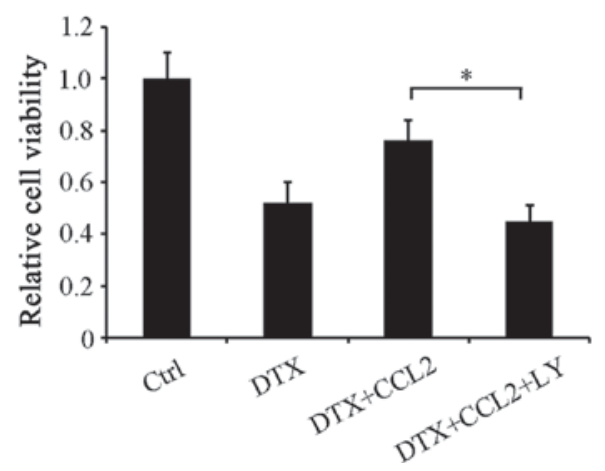

Figure 5. Phosphoinositide 3-kinase/AKT signaling pathway participates in the CCL2-mediated DTX-resistance response. A549 cells were treated with or without $4 \mathrm{nM}$ DTX or $5 \mu \mathrm{M} \mathrm{LY}$, or a combination, for $48 \mathrm{~h}$. (A) Western blot analysis was performed to examine the phosphorylation of AKT, Bcl-2 and Bad using their respective specific antibodies. Total AKT, Bcl-2 and Bad were used as loading controls. (B) Caspase-3 activity was detected using a human active caspase-3 ELISA. (C) Cell viability was evaluated using an MTT assay. ${ }^{*} \mathrm{P}<0.05$ with comparisons shown by lines. N.S., not significant; AKT, protein kinase B; CCL2, C-C motif chemokine ligand 2; DTX, docetaxel; LY, LY294002; Ctrl, control; p-, phosphorylated; AKT, protein kinase B; Bcl-2, B-cell lymphoma 2; Bad, Bcl-2-associated death promoter.

performed by QZ. TW and XP were the major contributors in analysis and interpretation of data and statistical analysis. Drafting the manuscript was performed by TW and XP.

\section{Ethics approval and consent to participate}

Not applicable. 


\section{Consent for publication}

Not applicable.

\section{Competing interests}

The authors declare that they have no competing interests.

\section{References}

1. PDQ Adult Treatment Editorial Board: Non-small cell lung cancer treatment $\left(\mathrm{PDQ}^{\circledR}\right)$ : Patient version. NCI. 2002-2015 May 12.

2. Evans TL: Chemotherapy in advanced non-small cell lung cancer: Optimal treatment approach for elderly and patients with poor performance status. Lung cancer. Am J Hemat Oncol 7: $12-16,2015$

3. Du Y, Su T, Zhao L, Tan X, Chang W, Zhang H and Cao G: Associations of polymorphisms in DNA repair genes and MDR1 gene with chemotherapy response and survival of non-small cell lung cancer. PLoS One 9: e99843, 2014.

4. Chen WL, Kuo KT, Chou TY, Chen CL, Wang CH, Wei YH and Wang LS: The role of cytochrome c oxidase subunit Va in non-small cell lung carcinoma cells: Association with migration, invasion and prediction of distant metastasis. BMC Cancer 12 273, 2012.

5. McKeage K: Docetaxel: A review of its use for the first-line treatment of advanced castration-resistant prostate cancer. Drugs 72: 1559-1577, 2012.

6. Lyseng-Williamson KA and Fenton C: Docetaxel: A review of its use in metastatic breast cancer. Drugs 65: 2513-2531, 2005.

7. Bayet-Robert M, Morvan D, Chollet P and Barthomeuf C: Pharmacometabolomics of docetaxel-treated human MCF7 breast cancer cells provides evidence of varying cellular responses at high and low doses. Breast Cancer Res Treat 120: 613-26, 2010

8. Niu L, Deng J, Zhu F, Zhou N, Tian K, Yuan H and Lou H: Anti-inflammatory effect of Marchantin M contributes to sensitization of prostate cancer cells to docetaxel. Cancer Lett 348: 126-134, 2014.

9. Kim E, Matsuse M, Saenko V, Suzuki K, Ohtsuru A, Mitsutake N and Yamashita S: Imatinib enhances docetaxel-induced apoptosis through inhibition of nuclear factor $-\kappa \mathrm{B}$ activation in anaplastic thyroid carcinoma cells. Thyroid 22: 717-724, 2012.

10. Wu H, Xin Y, Zhao J, Sun D, Li W, Hu Y and Wang S: Metronomic docetaxel chemotherapy inhibits angiogenesis and tumor growth in a gastric cancer model. Cancer Chemother Pharmacol 68: 879-887, 2011.

11. Zhang Y, Hu YL and Cheng YY: Docetaxel influences autocrine of transforming growth factors and induces apoptosis in human ovarian cancer cell line AO. Chin Med Sci J 21: 204, 2006

12. He X, Li C, Wu X and Yang G: Docetaxel inhibits the proliferation of non-small-cell lung cancer cells via upregulation of microRNA-7 expression. Int J Clin Exp Pathol 8: 9072-9080, 2015.

13. Indo $\mathrm{K}$, Hoshikawa $\mathrm{H}$, Kamitori $\mathrm{K}$, Yamaguchi $\mathrm{F}$, Mori $\mathrm{T}$, Tokuda $\mathrm{M}$ and Mori N: Effects of D-allose in combination with docetaxel in human head and neck cancer cells. Int J Oncol 45 2044-2050, 2014.

14. http://www.cancer.gov/cancertopics/druginfo/fda-docetaxel, National Cancer Institute, Last Updated 3: 28, 2014.

15. Huang CY, Beer TM, Higano CS, True LD, Vessella R, Lange PH, Garzotto M and Nelson PS: Molecular alterations in prostate carcinomas that associate with in vivo exposure to chemotherapy: Identification of a cytoprotective mechanism involving growth differentiation factor 15. Clin Cancer Res 13: 5825-5833, 2007.

16. De Marzo AM, Platz EA, Sutcliffe S, Xu J, Gronberg H, Drake CG, Nakai Y, Isaacs WB and Nelson WG: Inflammation in prostate carcinogenesis. Nat Rev Cancer 7: 256-269, 2007.

17. Seruga B, Zhang H, Bernstein LJ and Tannock IF: Cytokines and their relationship to the symptoms and outcome of cancer. Nat Rev Cancer 8: 887-899, 2008.

18. Chiba T, Marusawa $\mathrm{H}$ and Ushijima $\mathrm{T}$ : Inflammation-associated cancer development in digestive organs: Mechanisms and roles for genetic and epigenetic modulation. Gastroenterology 143 $550-563,2012$.
19. Kawanishi S, Ohnishi S, Ma N, Hiraku Y and Murata M: Crosstalk between DNA damage and inflammation in the multiple steps of carcinogenesis. Int J Mol Sci 18: 1808, 2017.

20. Ding N, Maiuri AR and O'Hagan HM: The emerging role of epigenetic modifiers in repair of DNA damage associated with chronic inflammatory diseases. Mutation Research-Reviews in Mutation Research: Online September 28, 2017. In Press.

21. Mantovani A, Allavena P, Sica A and Balkwill F: Cancer-related inflammation. Nature 454: 436-444, 2008.

22. Balkwill F: Cancer and the chemokine network. Nat Rev Cancer 4: 540-550, 2004.

23. Sica A, Wang JM, Colotta F, Dejana S, Mantovani A, Oppenheim JJ, Larsen CG, Zachariae CO and Matsushima K: Monocyte chemotactic and activating factor gene expression induced in endothelial cells by IL-1 and tumor necrosis factor. J Immunol 144: 3034-3038, 1990.

24. Carr MW, Roth SJ, Luther E, Rose SS and Springer TA: Monocyte chemoattractant protein 1 acts as a T-lymphocyte chemoattractant. Proc Natl Acad Sci USA 91: 3652-3656, 1994.

25. Xu LL, Warren MK, Rose WL, Gong W and Wang JM: Human recombinant monocyte chemotactic protein and other $\mathrm{C}-\mathrm{C}$ chemokines bind and induce directional migration of dendritic cells in vitro. J Leukoc Biol 60: 365-371, 1996.

26. Barcelos LS, Talvani A, Teixeira AS, Cassali GD, Andrade SP and Teixeira MM: Production and in vivo effects of chemokines CXCL1-3/KC and CCL2/JE in a model of inflammatory angiogenesis in mice. Inflamm Res 53: 576-584, 2004.

27. Zhang J, Lu Y and Pienta KJ: Multiple roles of chemokine (C-C motif) ligand 2 in promoting prostate cancer growth. J Natl Cancer Inst 102: 522-528, 2010.

28. Ajuebor MN, Swain MG and Perretti M: Chemokines as novel therapeutic targets in inflammatory diseases. Biochem Pharmacol 63: 1191-1196, 2002.

29. Said N, Sanchez-Carbayo M, Smith SC and Theodorescu D: RhoGDI2 suppresses lung metastasis in mice by reducing tumor versican expression and macrophage infiltration. J Clin Invest 122: 1503-1518, 2012.

30. Qian BZ, Li J, Zhang H, Kitamura T, Zhang J, Campion LR, Kaiser EA, Snyder LA and Pollard JW: CCL2 recruits inflammatory monocytes to facilitate breast-tumour metastasis. Nature 475: 222-225, 2011.

31. Abangan RS Jr, Williams CR, Mehrotra M, Duncan JD and Larue AC: MCP1 directs trafficking of hematopoietic stem cell-derived fibroblast precursors in solid tumor. Am J Pathol 176: 1914-1926, 2010.

32. Qian DZ, Rademacher BL, Pittsenbarger J, Huang CY, Myrthue A, Higano CS, Garzotto M, Nelson PS and Beer TM: CCL2 is induced by chemotherapy and protects prostate cancer cells from docetaxel-inducedcytotoxicity. Prostate 70: 433-442, 2010.

33. Kirk PS, Koreckij T, Nguyen HM, Brown LG, Snyder LA, Vessella RL and Corey E: Inhibition of CCL2 signaling in combination with docetaxel treatment has profound inhibitory effects on prostate cancer growth in bone. Int J Mol Sci 14: 10483-10496, 2013.

34. Fridlender ZG, Buchlis G, Kapoor V, Cheng G, Sun J, Singhal S, Crisanti MC, Wang LC, Heitjan D, Snyder LA and Albelda SM: CCL 2 blockade augments cancer immunotherapy. Cancer Res 70: 109-118, 2010.

35. Fridlender ZG, Kapoor V, Buchlis G, Cheng G, Sun J, Wang LC, Singhal S, Snyder LA and Albelda SM: Monocyte chemoattractant protein-1 blockade inhibits lung cancer tumor growth by altering macrophage phenotype and activating CD8+ cells. Am J Respir Cell Mol Biol 44: 230-237, 2011.

36. Livak KJ and Schmittgen TD: Analysis of relative gene expression data using real-time quantitative PCR and the 2(-Delta Delta C(T)) method. Methods 25: 402-408, 2001.

37. Qian DZ, Wei YF, Wang X, Kato Y, Cheng L and Pili R: Antitumor activity of the histone deacetylase inhibitor MS-275 in prostate cancer models. Prostate 67: 1182-1193, 2007.

38. Annovazzi L, Mellai M, Caldera V, Valente G, Tessitore L and Schiffer D: mTOR, S6 and AKT expression inrelation to proliferation and apoptosis/autophagy in glioma. Anticancer Res 29: 3087-3094, 2009.

39. Falasca M: PI3K/Akt signaling pathway specific inhibitors: A novel strategy to sensitize cancer cells to anti-cancer drugs. Curr Pharm Des 16: 1410-1416, 2010.

40. McCubrey JA, Steelman LS, Chappell WH, Abrams SL, Wong EW, Chang F, Lehmann B, Terrian DM, Milella M, Tafuri A, et al: Roles of the Raf/MEK/ ERK pathway in cell growth, malignant transformation and drug resistance. Biochim Biophys Acta 1773: 1263-1284, 2007. 
41. Datta SR, Dudek H, Tao X, Masters S, Fu H, Gotoh Y and Greenberg ME: Akt phosphorylation of BAD couples survival signals to the cell-intrinsic death machinery. Cell 91: 231-241, 1997.

42. Cardone MH, Roy N, Stennicke HR, Salvesen GS, Franke TF, Stanbridge E, Frisch S and Reed JC: Regulation of cell death protease caspase-9 by phosphorylation. Science 282: 1318-1321, 1998.

43. Mabuchi S, Ohmichi M, Kimura A, Hisamoto K, Hayakawa J, Nishio Y, Adachi K, Takahashi K, Arimoto-Ishida E, Nakatsuji Y, et al: Inhibition of phosphorylation of BAD and Raf-1 by Akt sensitizes human ovarian cancer cells to paclitaxel. J Biol Chem 277: 33490-33500, 2002.

44. She QB, Solit DB, Ye Q, O'Reilly KE, Lobo J and Rosen N: The BAD protein integrates survival signaling by EGFR/MAPK and PI3K/Akt kinase pathways in PTEN-deficient tumor cells. Cancer Cell 8: 287-297, 2005.

45. Basu A and Haldar S: Microtubule-damaging drugs triggered bcl2 phosphorylation-requirement of phosphorylation on both serine-70 and serine- 87 residues of bcl2 protein. Int J Oncol 13: 659-664, 1998.

46. Haldar S, Basu A and Croce CM: Serine-70 is one of the critical sites for drug-induced $\mathrm{Bcl} 2$ phosphorylation in cancer cells. Cancer Res 58: 1609-1615, 1998.
47. Wang TH, Wang HS, Ichijo H, Giannakakou P, Foster JS, Fojo T and Wimalasena J: Microtubuleinterfering agents activate c-Jun $\mathrm{N}$-terminal kinase/stress-activated protein kinase through both Ras and apoptosis signal-regulating kinase pathways. J Biol Chem 273: 4928-4936, 1998.

48. Yamamoto K, Ichijo H and Korsmeyer SJ: BCL-2 is phosphorylated and inactivated by an ASK1/Jun nterminal protein kinase pathway normally activated at G(2)/M. Mol Cell Biol 19: 8469-8478, 1999.

49. Tang XR and Amar S: p53 suppresses CCL2-induced subcutaneous tumor xenograft. Tumour Biol 36: 2801-2808, 2015.

50. Egunsola AT, Zawislak CL, Akuffo AA, Chalmers SA, Ewer JC, Vail CM, Lombardo JC, Perez DN and Kurt RA: Growth, metastasis, and expression of CCL 2 and CCL 5 by murine mammary carcinomas are dependent upon Myd88. Cell Immunol 272: 220-229, 2012

51. Liu T, Miao Z, Jiang J, Yuan S, Fang W, Li B and Chen Y: Visfatin mediates SCLC cells migration across brain endothelial cells through upregulation of CCL2. Int J Mol Sci 16: 11439-11451, 2015.

52. Wu FY, Fan J, Tang L, Zhao YM and Zhou CC: Atypical chemokine receptor D6 inhibits human non-small cell lung cancer growth by sequestration of chemokines. Oncol Lett 6: 91-95, 2013 